\title{
Acidithiobacillus ferrianus sp. nov.: an ancestral extremely acidophilic and facultatively anaerobic chemolithoautotroph
}

\author{
Paul R. Norris ${ }^{1,9} \cdot$ Carmen Falagán $^{2,3} \cdot$ Ana Moya-Beltrán ${ }^{4,6} \cdot$ Matías Castro $^{4,8} \cdot$ Raquel Quatrini $^{4,5,7} \cdot$ D. Barrie Johnson ${ }^{3}$
}

Received: 4 December 2019 / Accepted: 10 January 2020 / Published online: 24 January 2020

(c) The Author(s) 2020

\begin{abstract}
Strain MG, isolated from an acidic pond sediment on the island of Milos (Greece), is proposed as a novel species of ferrous iron- and sulfur-oxidizing Acidithiobacillus. Currently, four of the eight validated species of this genus oxidize ferrous iron, and strain MG shares many key characteristics with these four, including the capacities for catalyzing the oxidative dissolution of pyrite and for anaerobic growth via ferric iron respiration. Strain MG also grows aerobically on hydrogen and anaerobically on hydrogen coupled to ferric iron reduction. While the $16 \mathrm{~S}$ rRNA genes of the iron-oxidizing Acidithiobacillus species (and strain MG) are located in a distinct phylogenetic clade and are closely related (98-99\% 16S rRNA gene identity), genomic relatedness indexes (ANI/dDDH) revealed strong genomic divergence between strain MG and all sequenced type strains of the taxon, and placed MG as the first cultured representative of an ancestral phylotype of iron oxidizing acidithiobacilli. Strain MG is proposed as a novel species, Acidithiobacillus ferrianus sp. nov. The type strain is $\mathrm{MG}^{\mathrm{T}}\left(=\mathrm{DSM} 107098^{\mathrm{T}}=\mathrm{JCM} 33084^{\mathrm{T}}\right)$. Similar strains have been found as isolates or indicated by cloned 16S rRNA genes from several mineral sulfide mine sites.
\end{abstract}

Keywords Acidithiobacillus ferrianus $\cdot$ Ferrous iron oxidation $\cdot$ Ferric iron reduction $\cdot$ Hydrogen oxidation $\cdot$ Sulfur oxidation

Communicated by A. Oren.

Electronic supplementary material The online version of this article (https://doi.org/10.1007/s00792-020-01157-1) contains supplementary material, which is available to authorized users.

D. Barrie Johnson

d.b.johnson@bangor.ac.uk

1 School of Biological Sciences, University of Warwick, Coventry, UK

2 Environment and Sustainability Institute and Camborne School of Mines, University of Exeter, Penryn, UK

3 School of Natural Sciences, Bangor University, Bangor, UK

4 Fundación Ciencia y Vida, Santiago, Chile

5 Universidad San Sebastian, Santiago, Chile

6 Facultad de Ciencias de la Vida, Universidad Andres Bello, Santiago, Chile

7 Millennium Nucleus in the Biology of Intestinal Microbiota, Santiago, Chile

8 Facultad de Ingeniería y Tecnología, Universidad San Sebastián, Concepción, Chile

9 Present Address: College of Engineering, Maths and Physical Sciences, University of Exeter, Penryn Campus, Penryn, Cornwall TR10 9FE, UK

\section{Abbreviations}

dDDH In silico DNA-DNA hibridization

$\mathrm{ANIb}^{2}$ Average Nucleotide Identity using blast

$\mathrm{ANIm}^{2}$ Average Nucleotide Identity using MUMmer

\section{Introduction}

The genus Acidithiobacillus [phylum Proteobacteria, class Acidithiobacillia (Kelly and Wood 2000; Williams and Kelly 2013] currently includes eight validated species, which are found typically in low $\mathrm{pH}$ environments such as waste dumps at metal and coal mines and acidic waters draining from mine-impacted sites. All of these species can grow autotrophically using zero-valent (elemental) sulfur and sulfide, and sulfur-oxyanions that are more reduced than sulfate, as electron donors. Four of the species can oxidize ferrous iron: A. ferrivorans (Hallberg et al. 2010), A. ferridurans (Hedrich and Johnson 2013a), A. ferriphilus (Falagán and Johnson 2016) and the most studied iron-oxidizing species, A. ferrooxidans (Kelly and Wood 2000). Although ferric iron reduction may be observed in sulfur-containing cultures of all Acidithiobacillus spp., even under aerobic conditions, 
growth by ferric iron respiration appears to be restricted to those species that also oxidize iron (Hallberg et al. 2001; Johnson et al. 2017). Some acidithiobacilli can also use hydrogen as sole electron donor, but while this appears to be a common trait for all strains of some species (A. ferrooxidans and A. ferridurans) this is not the case for strains of other species (A. ferrivorans, A. thiooxidans and A. caldus) and has not been observed in any strain of $A$. ferriphilus (Hedrich and Johnson 2013b; Falagán and Johnson 2016).

The four currently-validated species of iron-oxidizing Acidithiobacillus share 98-99\% identity of their 16S rRNA gene sequences but different species designations have been confirmed by comparison of additional marker genes (Amouric et al. 2011), MLSA-based phylogenies and oligotyping analysis (Nuñez et al. 2017). Several additional phylotypes have been identified among acidithiobacilli isolates and 16S rRNA gene sequence clones (Nuñez et al. 2017), a number of which currently lack cultured representatives and diagnostic phenotypic properties.

Here we describe strain MG, isolated from an acidic pond on the island of Milos (Greece), which represents a novel, ancestral phylotype of iron-oxidizing acidithiobacilli (phylotype 3A of Nuñez et al. 2017) and we present chemotaxonomic and genomic taxonomy data to support its recognition as a fifth iron oxidizing species, A. ferrianus $\mathrm{MG}^{\mathrm{T}}$.

\section{Materials and methods}

\section{Growth conditions}

The liquid medium for growth with ferrous iron as substrate contained $\left(\mathrm{g} \mathrm{1}^{-1}\right)\left(\mathrm{NH}_{4}\right)_{2} \mathrm{SO}_{4},(0.4), \mathrm{MgSO}_{4} \cdot 7 \mathrm{H}_{2} \mathrm{O}(0.5)$, $\mathrm{K}_{2} \mathrm{HPO}_{4}(0.2)$ and $\mathrm{FeSO}_{4} \cdot 7 \mathrm{H}_{2} \mathrm{O}\left(13.9 \mathrm{~g}^{-1}\right.$; equivalent to $50 \mathrm{mM}$ ferrous iron), adjusted to $\mathrm{pH} 1.7$ with $\mathrm{H}_{2} \mathrm{SO}_{4}$. Basal salts solutions were sterilized at $120^{\circ} \mathrm{C}$ for $20 \mathrm{~min}$, and ferrous sulfate solutions by filtering through $0.2 \mu \mathrm{m}$ (pore size) membrane filters. For growth with sulfur (sterilized by Tyndallization), $\mathrm{FeSO}_{4} \cdot 7 \mathrm{H}_{2} \mathrm{O}$ was lowered to $10 \mathrm{mg} 1^{-1}$ $(0.18 \mathrm{mM})$ sulfur powder $\left(5 \mathrm{~g} \mathrm{l}^{-1}\right)$ added and $\mathrm{pH}$ adjusted to $\mathrm{pH}$ 3. Biomass particle analysis used a CellFacts Particle Size Analyzer (CellFacts Instruments, Coventry, UK). The ferrous iron medium was solidified with Phytagel $(0.4 \%$, w/v) for initial single colony isolation. Further growth studies with solid media used ferrous iron overlay plates (Johnson and Hallberg 2007). For solid medium anaerobic growth, oxygen was removed from sealed incubation jars containing activated carbon (AnaeroGen system, Fisher, U.K).

\section{Phenotype and chemotaxonomy observations}

For scanning electron microscopy, cells were grown in basal salts/trace elements medium (Ñancucheo et al. 2016) containing sulfur as sole electron donor at $30{ }^{\circ} \mathrm{C}$. Sulfur coupons were prepared as described by Castro et al. (2015). Samples were critical point dried, coated with gold and observed with a LEO 1420VP scanning electron microscope. For transmission electron microscopy, cells were grown aerobically at $30{ }^{\circ} \mathrm{C}$ to mid-exponential phase in basal salts/trace elements medium containing $2.5 \mathrm{mM}$ potassium tetrathionate. Planktonic cells were harvested and fixed in $4 \%$ paraformaldehyde overnight. Samples were loaded onto a collodion-coated copper grid and stained with $1 \%(\mathrm{w} / \mathrm{v})$ uranyl acetate. Samples were observed using a Philips Tecnai 12 (Biotwin) transmission electron microscope.

Strain MG was grown aerobically at $30{ }^{\circ} \mathrm{C}$ with hydrogen as substrate to provide biomass for analysis of fatty acids, polar lipids and respiratory quinones biomass at the DSMZ (Deutsche Sammlung von Mikroorganismen und Zellkulturen, Braunschweig, Germany). Chromosomal base composition was determined by thermal denaturation (Norris et al. 1996).

\section{Genome sequencing, molecular and phylogenetic analysis}

Total DNA was extracted from strain MG following lysozyme treatment of cells grown on hydrogen. The genome was sequenced using paired-end libraries with insert size of $\sim 460$ bp (Nextera DNA Sample Preparation kit) and Illumina Hiseq sequencing technology (CD-Genomics, US). Reads were processed and assembled as described by Castro et al. (2017). The final draft assembly contained 90 contigs (N50 222, 906) and an average depth coverage of 33.42-fold adding up 3.2 Mbp in total. This whole-genome shotgun project has been deposited at GenBank under the accession number WNJL00000000. The version described in this paper is version WNJL01000000. The average nucleotide identities between the draft genome and those of the reference type strains of Acidithiobacillus spp. were calculated using a Python module implemented by Goris et al. (2007) and available at http://widdowquinn.githu b.io/pyani/PYANI. The dDDH values between strains were calculated using the Genome-to-Genome Distance Calculator (GGDC) web server (Meier-Kolthoff et al. 2013). Analysis of the 16S rRNA gene used the complete sequence (MN733279) retrieved from the genome using BARNAP (BAsic Rapid Ribosomal RNA Predictor version $0.9-\mathrm{dev}$ ). This gene was $100 \%$ identical to the $16 \mathrm{~S}$ rRNA gene sequence originally deposited in GenBank (MG062778) after the initial single colony isolation. The phylogeny of strain MG was assessed from the small subunit ribosomal RNA gene sequences alignment (MAFFT v7.229) (Katoh and Standley 2013), after manual trimming and masking (>50\%). Phylogenetic trees were 
reconstructed with two different algorithms (NeighborJoining and Maximum-Likelihood; Falagán et al. 2019) and their topologies compared. The consensus tree was constructed using PHYLIP (Shimada and Nishida 2017).

\section{Results and discussion}

\section{Isolation and distribution}

Strain MG was isolated from sediment of an acidic pond (approximately $12 \mathrm{~m}^{2}$ surface area) close to the geothermal site at Kalamos on the South coast of the island of Milos, Greece (Supplementary Fig. S1). The water was at ambient temperature, lightly coloured green from growth of unicellular algae, and was $\mathrm{pH} 3.5$. There were patches of land surface in the area that were more acidic at about $\mathrm{pH}$ 2. The water was essentially chloride-free and contained $5 \mathrm{mg}^{-1}$ ferrous iron. Ferrous iron oxidation was observed in a ferrous iron enrichment culture $(\mathrm{pH} 2)$ of sediment from the pond margin and ferric iron-encrusted colonies were readily obtained on Phytagel-solidified medium containing $25 \mathrm{mM}$ ferrous iron at $\mathrm{pH} 2$. All colonies were of similar appearance and size. Identical 16S rRNA gene sequences were obtained from the two of the colonies that were examined. Two closely related ironoxidizing acidithiobacilli have been isolated from sites in China and similar bacteria from other mine-impacted environments in China and the USA have been indicated by highly similar 16S rRNA gene sequences (between 98 and $99 \%$ identity to that of strain MG; Table 1). These isolates, clones and isolate MG could represent strains of the same species.

\section{Phylogeny and genomic comparisons}

Phylogenetic analysis of the 16S rRNA gene sequences placed strain MG outside the clade grouping the other iron-oxidizing members of the genus (Fig. 1) suggesting it represents an ancestral phylotype of iron-oxidizing acidithiobacilli, phylotype 3A of Nuñez et al. (2017). Limited disagreement in topology was observed between trees built using Neighbour-Joining and Maximum-Likelihood methods (Supplementary Fig. S2). Comparison of the sequences of strain MG and type strains of the genus Acidithiobacillus revealed identity differences (Table 2) which fall above the proposed species level cut-off value of $>1.3 \%$ (Stackebrandt and Ebers 2006), except in the case of A. ferriphilus and A. ferridurans for which the difference is marginally within this cut-off value. Four distinct clades comprising isolates of the four previously named ferrous iron-oxidizing species and a fifth for strain MG were also seen in re-construction of phylogenetic trees of two ( $\mathrm{rec} A$ and $a t p D)$ marker genes previously used (Amouric et al. 2011) to illustrate the genetic diversity of A. ferrooxidans-like isolates (Supplementary Fig. S3). Genomic relatedness indices further supported differentiation of strain MG from the named iron-oxidizing Acidithiobacillus species. Pairwise comparisons between strain MG and the available reference genomes (Table 3) gave values, in both cases, well below the established thresholds used for prokaryotic species delimitation. A DNA:DNA hybridization of about $35 \%$ for strain MG against $A$. ferrooxidans (using digoxigenin nucleic acid labelling and chemiluminescence detection) suggested a similar divergence between the type strains of these species to those of the type strains of A. ferrooxidans from A. ferrivorans and A. ferriphilus (L. Laigle and P. Norris, unpublished data).
Table 1 Origins of isolates and clones with 16S rRNA gene sequences which have greater than $99.6 \%$ identity to that of strain MG

\begin{tabular}{|c|c|c|}
\hline & & GenBank acc. no. \\
\hline \multicolumn{3}{|l|}{ Isolates } \\
\hline LMT1 & $\begin{array}{l}\text { Mine tailings, Lechang, China; } \\
\text { pH } 1.9 \text { (Tan et al. 2008) }\end{array}$ & AM502930 \\
\hline Ish-01 & Soil, China & EU158322 \\
\hline \multicolumn{3}{|l|}{ Clones } \\
\hline Fe-K6-C12 & $\begin{array}{l}\text { Mine tailings, Klondykee Mill, USA; } \\
\text { pH } 5.7 \text { (Méndez et al. 2008) }\end{array}$ & EF612430 \\
\hline K6-C79 & $\begin{array}{l}\text { Mine tailings, Klondykee Mill, USA; } \\
\text { pH } 5.7 \text { (Méndez et al. 2008) }\end{array}$ & EF612421 \\
\hline AMD-A14 & $\begin{array}{l}\text { Jinkouling tailings pond, Tongling, China; } \mathrm{pH} 2.65 \text { (Yang } \\
\text { et al. 2014) }\end{array}$ & KC620596 \\
\hline AMD-D35 & $\begin{array}{l}\text { Shuimuchong tailings pond, Tongling, China; } \mathrm{pH} 2.1 \\
\text { (Yang et al. 2014) }\end{array}$ & KC620779 \\
\hline G28 & $\begin{array}{l}\text { Yunfu sulfide mine, Guangdong, China; } \\
\text { pH } 2.5 \text { (He et al. 2007) }\end{array}$ & DQ480479 \\
\hline $\mathrm{X} 18$ & Copper sulfide ore bioleaching heap, China & FJ268717 \\
\hline
\end{tabular}


Fig. 1 Consensus phylogenetic tree derived from the 16S rRNA gene sequences showing the relationship of strain MG with the type strains of the species with valid names of the genus Acidithiobacillus and Thermithiobacillus, the only other known genus in the Class. The gammaproteobacterium Methylococcus capsulatus ACM 3302 was used as outgroup. Bootstrap values are indicated at the respective nodes in the consensus tree derived from ML, NJ and BI phylogenetic treeing algorithms. Scale bar: $0.07 \%$ sequence divergence

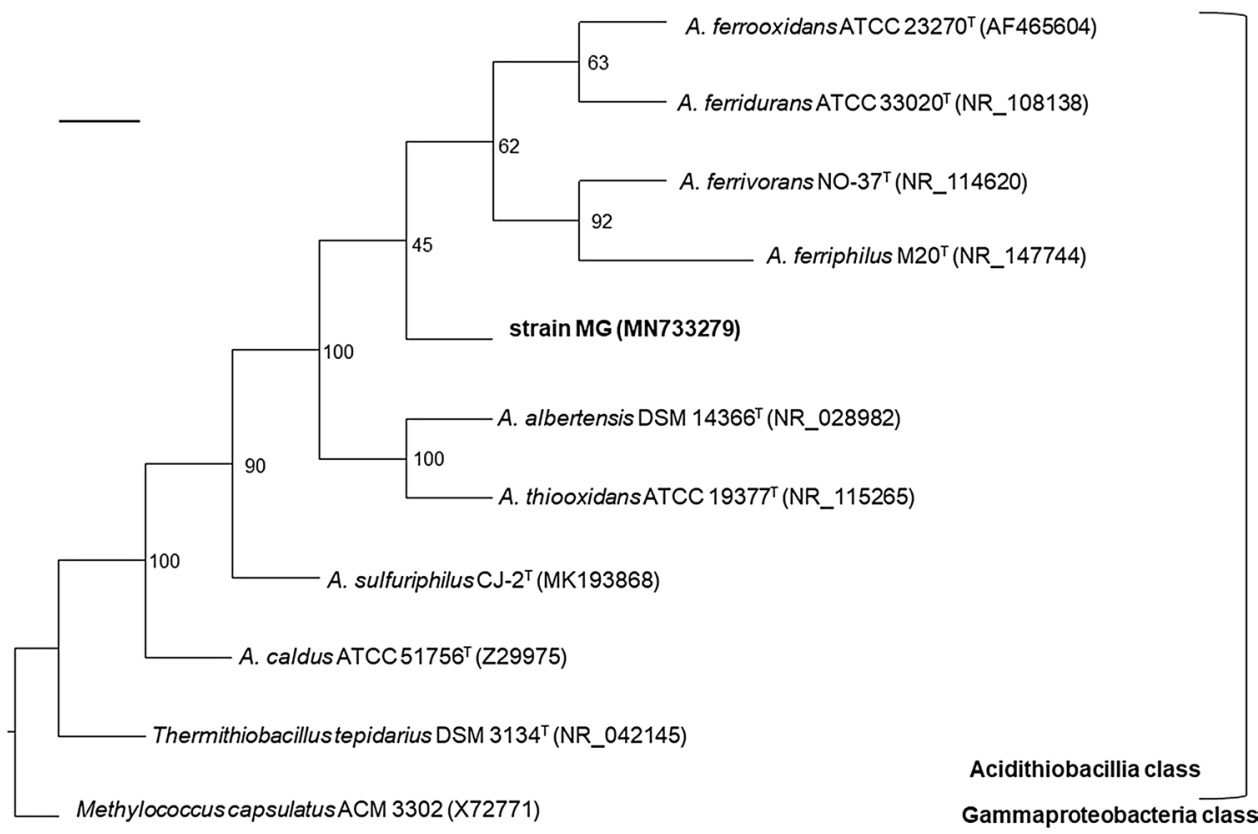

Table 2 Identities of the strain MG 16S rRNA gene to those of Acidithiobacillus type strains (from alignment of the regions between nucleotide coordinates 31 and 1488; sequences recovered from GenBank(nr) and RefSeq databases)

\begin{tabular}{|c|c|c|}
\hline Accession number & Species & $\%$ Identity \\
\hline MN733279a; MG062778 & Strain MG & 100.00 \\
\hline NR_147744 & Acidithiobacillus ferriphilus $^{\mathrm{T}}$ & 98.87 \\
\hline NR_108138 & Acidithiobacillus ferridurans $^{\mathrm{T}}$ & 98.86 \\
\hline AF465604 & $\begin{array}{l}\text { Acidithiobacillus ferroox- } \\
\text { idans }^{\mathrm{T}}\end{array}$ & 98.56 \\
\hline NR_114620 & Acidithiobacillus ferrivorans ${ }^{\mathrm{T}}$ & 98.31 \\
\hline NR_028982 & Acidithiobacillus albertensis $^{\mathrm{T}}$ & 98.13 \\
\hline NR_115265 & Acidithiobacillus thiooxidans $^{\mathrm{T}}$ & 97.11 \\
\hline KX426303 & $\begin{array}{l}\text { Acidithiobacillus sulfuriphi- } \\
\operatorname{lus}^{\mathrm{T}}\end{array}$ & 97.14 \\
\hline Z29975 & Acidithiobacillus caldus $^{\mathrm{T}}$ & 95.63 \\
\hline
\end{tabular}

${ }^{a} 16 \mathrm{~S}$ rRNA gene sequence retrieved from the MG strain genome using BARNAP (BAsic Rapid Ribosomal RNA Predictor version 0.9dev)

\section{Phenotypic characteristics}

Scanning electron microscopy showed attached cells and copious biofilms of sulfur-grown strain MG (Fig. 2a). A polar flagellum was observed during growth with tetrathionate (Fig. 2b). Flagellated cells swimming in tight groups were also observed, suggesting that strain MG has the capacity to swarm (data not shown). Motility was also observed during growth on ferrous iron.

In liquid media containing ferrous iron as sole electron donor, strain MG grew with a culture doubling time
Table 3 Genomic relatedness indexes (\%) calculated between strain MG and acidithiobacilli reference strains

\begin{tabular}{|c|c|c|c|c|}
\hline Accession no. & Strain & $\mathrm{dDDH}^{\mathrm{a}}$ & $\mathrm{ANIb}^{\mathrm{b}}$ & $\mathrm{ANIm}^{\mathrm{b}}$ \\
\hline WNJL01 & $\begin{array}{l}\text { Strain MG DSM } \\
107098^{\mathrm{T}}\end{array}$ & 100.00 & 100.00 & 100.00 \\
\hline NC_015942 & A. ferrivorans SS3 & 25.00 & 81.28 & 85.57 \\
\hline LVXZ01 & A. ferriphilus BY0502 & 25.40 & 81.07 & 85.56 \\
\hline NC_011761 & $\begin{array}{l}\text { A. ferro-oxidans ATCC } \\
23270^{\mathrm{T}}\end{array}$ & 24.60 & 80.93 & 85.57 \\
\hline NZ_AP018795 & $\begin{array}{l}\text { A. ferridurans } \\
\text { JCM18981 }\end{array}$ & 24.30 & 80.37 & 85.23 \\
\hline RIZI01 & $\begin{array}{l}\text { A. sulfuriphilus DSM } \\
105150^{\mathrm{T}}\end{array}$ & 21.80 & 74.75 & 86.20 \\
\hline AF0H01 & $\begin{array}{l}\text { A. thiooxidans ATCC } \\
19377^{\mathrm{T}}\end{array}$ & 19.80 & 74.24 & 84.82 \\
\hline MOAD01 & $\begin{array}{l}\text { A. albertensis DSM } \\
14366^{\mathrm{T}}\end{array}$ & 20.20 & 74.27 & 83.62 \\
\hline CO005986 & A. caldus ATCC $51756^{\mathrm{T}}$ & 19.00 & 72.81 & 86.56 \\
\hline AUIS01 & $\begin{array}{l}\text { T. tepidarius DSM } \\
3134^{\mathrm{T}}\end{array}$ & 19.30 & 71.97 & 83.12 \\
\hline
\end{tabular}

aDNA-DNA hybridization species-level cutoff: > 70 (Meier-Kolthoff et al. 2013)

${ }^{\mathrm{b}}$ Average Nucleotide Identity using BLAST (ANIb) and MUMmer (ANIm) species-level cutoff: $>95.9$ (Goris et al. 2007)

of between 6 and $7 \mathrm{~h}$ at an optimum temperature between 28 and $30{ }^{\circ} \mathrm{C}$ (Fig. 3a). Particle size analysis indicated little size change or aggregation of single and dividing cells over a temperature range of about $20{ }^{\circ} \mathrm{C}$ to at least $32{ }^{\circ} \mathrm{C}$ (Fig. 3a). Growth on ferrous iron was slightly slower at an initial culture medium $\mathrm{pH}$ of 2.0 than at $\mathrm{pH} 1.7$ (data not shown). The mechanism of ferrous iron oxidation by strain 

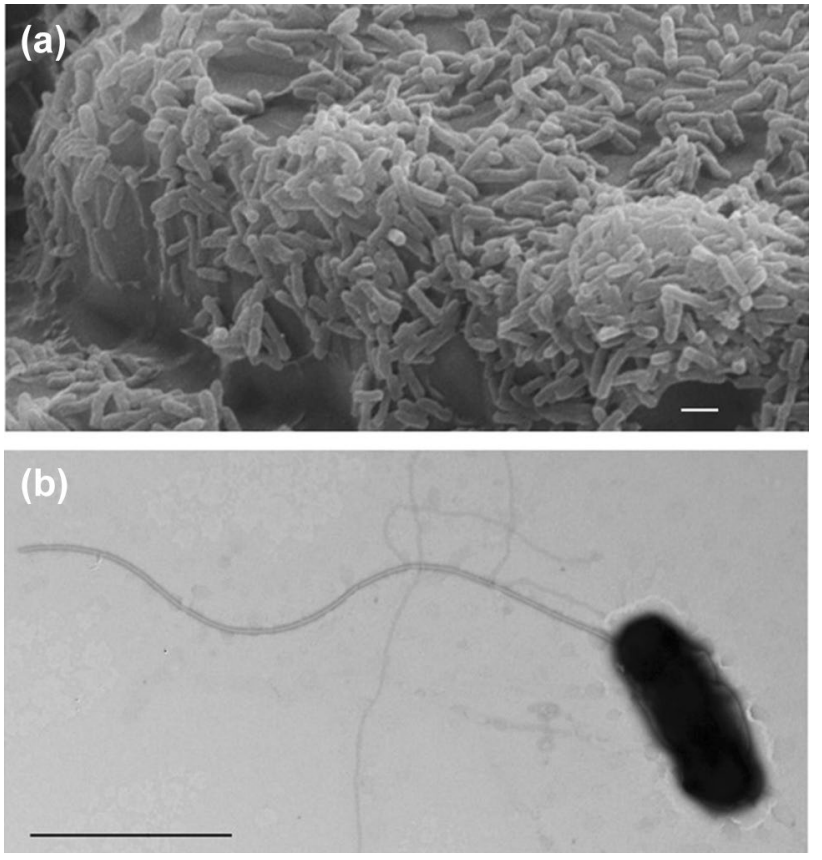

Fig. 2 Representative images of strain MG under substrate-attached and planktonic growth conditions. a Scanning electron microscopy (SEM) of strain MG attached on sulfur coupons during biofilm development. Scale bar, $1 \mu \mathrm{m}$. b Transmission electron microscopy (TEM) of a single motile cell showing a monopolar flagellum. Scale bar, $1 \mu \mathrm{m}$
MG could involve the rus operon, which is found in all of the iron-oxidizing acidithiobacilli, with key electron transport proteins rusticyanin and Cyc2 of strain MG sharing 94 and $85 \%$ amino acid identity respectively with those of $\mathrm{A}$. $\mathrm{fer}$ rooxidans $^{\mathrm{T}}$ (Norris et al. 2018).

The optimum $\mathrm{pH}$ for aerobic growth with hydrogen as sole substrate was circa. $\mathrm{pH} 2.2$ with incubation under $\mathrm{H}_{2} /$ $\mathrm{CO}_{2}$-enriched air (Fig. 3b), where high cell densities $\left(>10^{9}\right.$ cells $\mathrm{m} \mathrm{l}^{-1}$ ) were reached in liquid medium which contained basal salts, trace elements and $25 \mu \mathrm{M}$ ferrous iron. Addition of yeast extract $(0.02 \% \mathrm{w} / \mathrm{v})$ or glycerol $(5 \mathrm{mM})$ to ferrous iron liquid medium did not result in any increase in cell numbers of strain MG in oxidized cultures (data not shown) suggesting that, like other Acidithiobacillus spp., it is an obligate autotroph.

Ferric iron-encrusted colonies of strain MG grew on ferrous iron overlay plates that were incubated under $\mathrm{H}_{2} /$ $\mathrm{CO}_{2}$-enriched air. The morphology of colonies was similar initially to that of those incubated under air but, with more protracted (2-3 weeks) incubation, the colonies developed off-white gelatinous secondary growths that eventually occluded the iron-encrusted zones. When the secondary growths were re-streaked onto fresh plates and incubated under $\mathrm{H}_{2} / \mathrm{CO}_{2}$-enriched air, most colonies did not accumulate ferric iron, though a minority appeared to revert to oxidizing iron (Supplementary Fig. S4a). Two distinct non-iron-encrusted colony morphologies were found, one

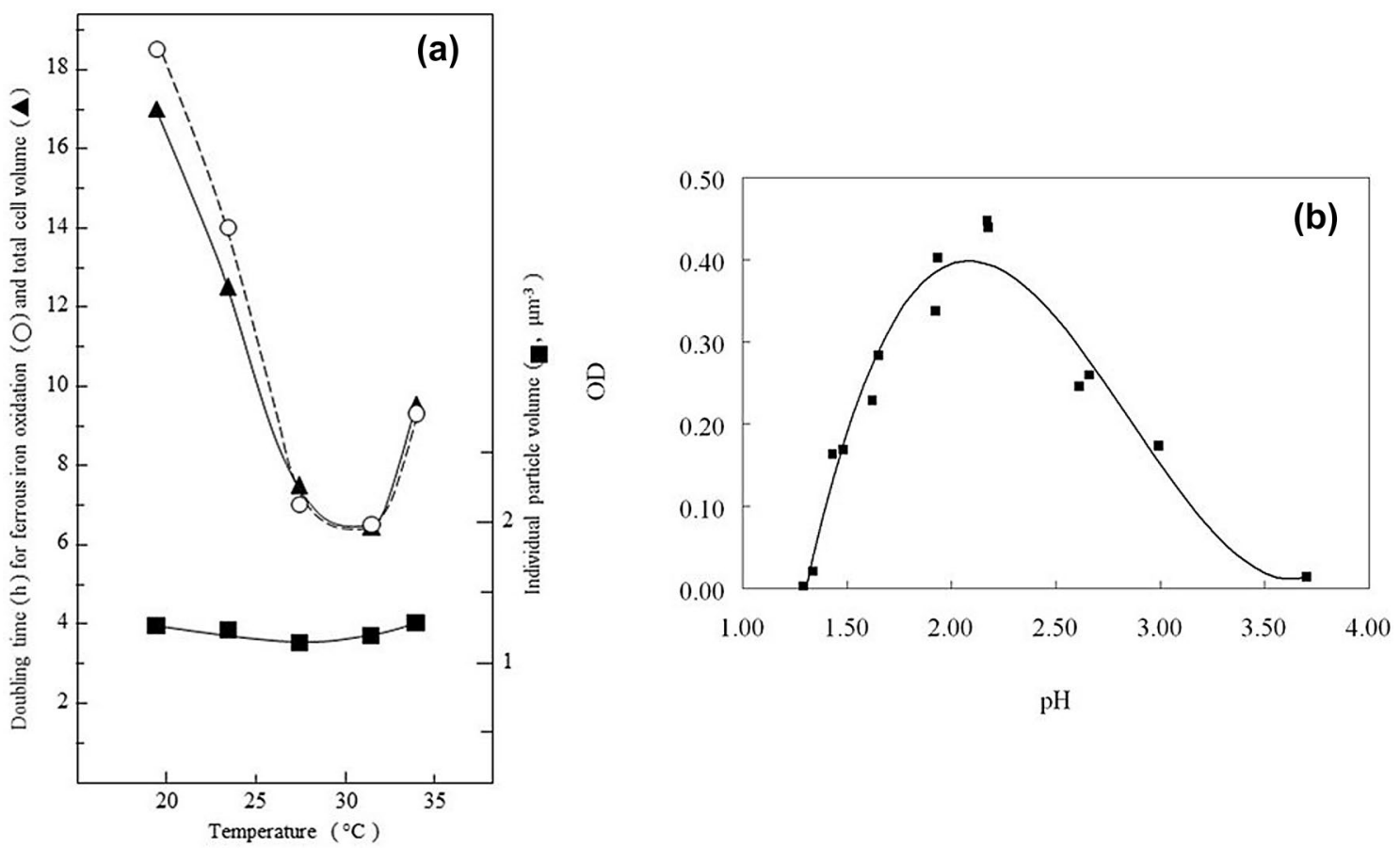

Fig. 3 Effect of temperature on growth of strain MG with ferrous iron as electron donor (a), and of pH with hydrogen as electron donor (b) 
smooth and the other larger and crustose (Supplementary Fig. S4b). These morphologies were retained when single colonies were sub-cultured. 16S rRNA genes from the three colony variants (ferric iron-encrusted, off-white smooth and crustose forms) were all identical to those from ferrous ironand sulfur-grown strain MG. Growth with hydrogen as sole electron donor also occurred anaerobically in the presence of ferric iron, with cell numbers correlating with the amount of iron reduced demonstrating that in common with other

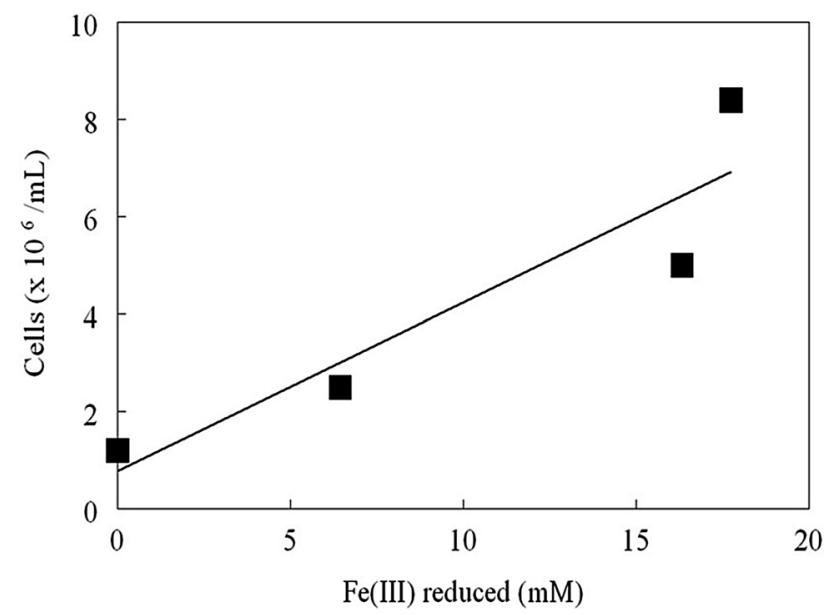

Fig. 4 Correlation between cell numbers of strain MG and ferric iron reduced with hydrogen as electron donor and ferric iron as electron acceptor iron-oxidizing acidithiobacilli, strain $\mathrm{MG}$ is a facultative anaerobe (Fig. 4).

Autotrophic growth of strain MG with sulfur as electron donor could also be coupled to either oxygen or ferric iron as electron acceptors. Strain MG appeared to have a longer lag phase on serial sub-culturing with sulfur than A. ferrooxidans (Fig. 5). Both species showed a similar response to oxygen depletion after addition of ferrous iron (as ferrous sulfate) to cells growing on sulfur. Acid-consuming ferrous iron oxidation was followed by reduction of the ferric iron produced and further acidification when oxygen became depleted in sealed flasks (Fig. 5), suggesting strain MG grew anaerobically using ferric iron to oxidize sulfur, as shown for A. ferrooxidans (Pronk et al. 1992), A. ferridurans (Hedrich and Johnson 2013a, b), A. ferrivorans (Hallberg et al. 2010) and A. ferriphilus (Falagán and Johnson 2016).

In common with other ferrous iron-oxidizing acidithiobacilli, strain MG catalyzed the oxidative dissolution of pyrite with concomitant increases in soluble iron and redox potential during growth (Supplementary Fig. S5). Even without prior adaptation, strain MG tolerated high concentrations of transition metals in solution but was highly sensitive to molybdenum (which exists predominantly as non-dissociated molybdic acid at $\mathrm{pH} 2$ ), as is seen with other iron-oxidizing acidophiles (Supplementary Table S1). It was also found to be highly osmotolerant, growing in media containing $>1 \mathrm{M}$ magnesium sulfate,
Fig. 5 Growth of strain $\mathrm{MG}$ and A. ferrooxidans ATCC $23270^{\mathrm{T}}$ at $30{ }^{\circ} \mathrm{C}$ with elemental sulfur, showing initial oxidation of ferrous iron $\left(0.9 \mathrm{~g} \mathrm{l}^{-1}\right.$ added at the times indicated by arrows) followed by reduction of produced ferric iron when oxygen became depleted in sealed flasks
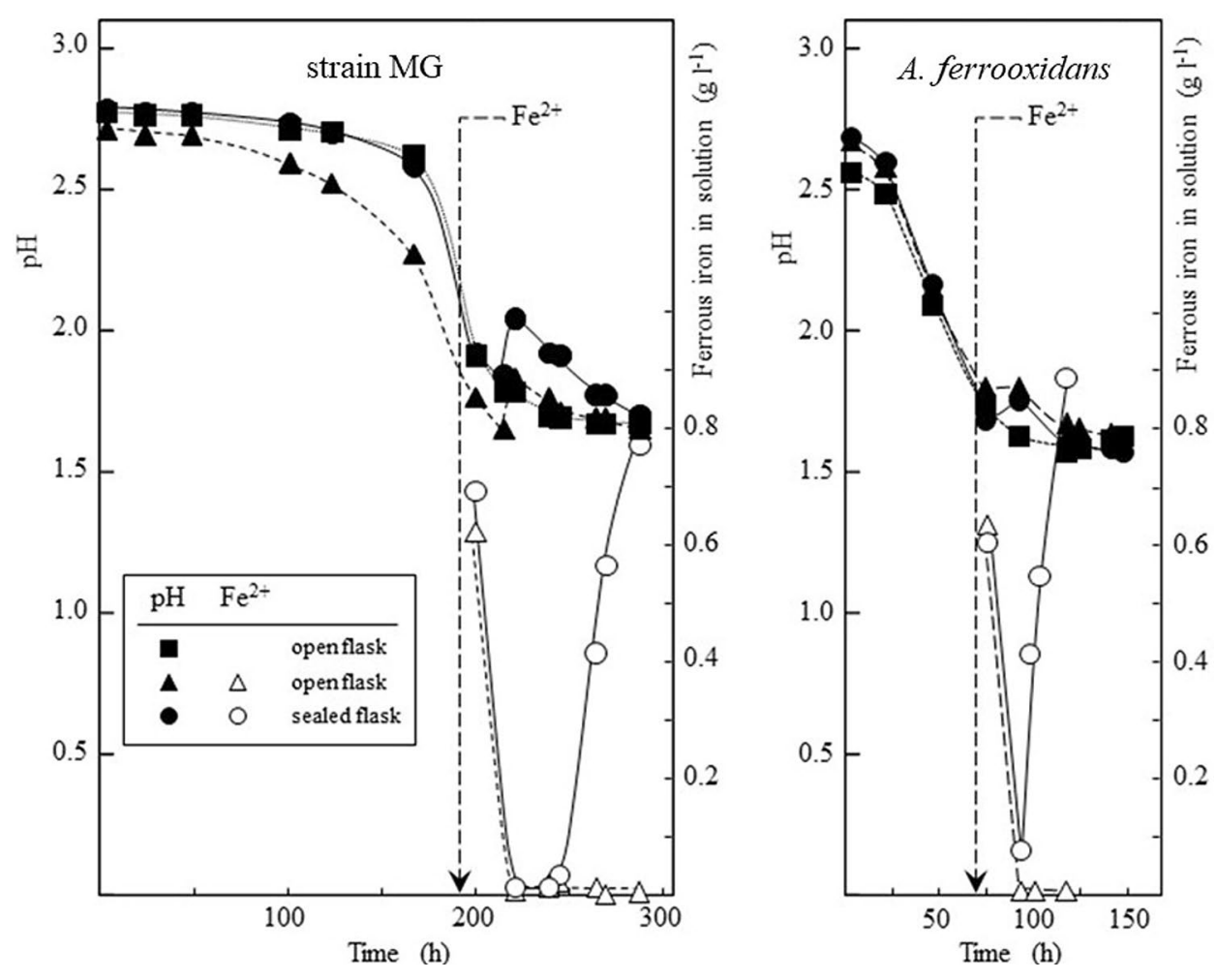
but it was more sensitive to (sodium) chloride, with no growth observed (at $\mathrm{pH}$ 2) with $>0.3 \mathrm{M} \mathrm{NaCl}$.

\section{Chemotaxonomic analyses}

The major fatty acids of strain $\mathrm{MG}, \mathrm{C}_{18: 1} \omega 7 \mathrm{c}, \mathrm{C}_{16: 1} \omega 7 \mathrm{c} /$ $\mathrm{C}_{16: 1} \omega 6$ and $\mathrm{C}_{16: 0}$, were similar in relative abundance to those reported for other iron-oxidizing acidithiobacilli (Table 4; no published data are available for A. ferrivorans). The major polar lipids of strain MG were aminolipid, phosphatidylglycerol and phosphotidylethanolamine, and the major quinone present (95\%) was Q8 (as also reported for A. ferridurans (Hedrich and Johnson 2013a, b) and A. ferriphilus (Falagán and Johnson 2016)) with smaller amounts of Q7 (5\%). Summed features represent groups of two or three fatty acids that could not be separated by GLC with the MIDI system. Summed feature 1 contains iso- $\mathrm{C}_{15: 1}$ and/or iso- $\mathrm{C}_{13: 0} 3-\mathrm{OH}$.; summed feature 2 contains $\mathrm{C}_{14: 0} 3-\mathrm{OH}$ and/ or iso- $\mathrm{C}_{16: 1}$; summed feature 3 contains $\mathrm{C}_{16: 1} \omega 7 \mathrm{c}, \mathrm{C}_{16: 1} \omega 6 \mathrm{c}$ and/or iso- $\mathrm{C}_{15: 0} 2-\mathrm{OH}$; summed feature 8 contains $\mathrm{C}_{18: 1} \omega 7 \mathrm{c}$ and/or $\mathrm{C}_{18: 1} \omega \mathrm{6c}$.

The mean base composition of the chromosomal DNA of strain MG was determined as $58 \mathrm{~mol} \% \mathrm{G}+\mathrm{C}$ by thermal denaturation and the draft genome contigs have an average of $58.2 \mathrm{~mol} \% \mathrm{G}+\mathrm{C}$. All previously described ironoxidizing acidithiobacilli have DNA containing between 56 and $59 \mathrm{~mol} \% \mathrm{G}+\mathrm{C}$.

In summary, a species designation for strain $\mathrm{MG}$ is strongly supported by different pieces of evidence, including $16 \mathrm{~S}$ rRNA and marker gene-based taxonomy, genomic taxonomy and chemotaxonomy. Overall genome relatedness indices derived from the available genome sequences of the taxon are in line with DNA:DNA hybridization values and provide strong evidence supporting the genomic divergence of strain MG and currently acknowledged type strains of the taxon. Of particular interest was the observation that strain MG is the first characterized representative of an ancestral phylotype of iron oxidizing acidithiobacilli. Further isolations will be required to elucidate
Table 4 Cellular fatty acids (shown as percentage values) of strain $\mathrm{MG}$ grown on hydrogen at $\mathrm{pH} 2$ and $30^{\circ} \mathrm{C}$ and comparison with values reported for the type strains of iron-oxidizing Acididthiobacillus spp. (Falagán and Johnson 2016). Summed features represent groups of two or three fatty acids that could not be separated by GLC with the MIDI system. *Summed feature 1 contains iso- $\mathrm{C}_{15: 1}$ and/ or iso- $\mathrm{C}_{13: 0} 3-\mathrm{OH}$.; summed feature 2 contains $\mathrm{C}_{14: 0} 3-\mathrm{OH}$ and/or iso- $\mathrm{C}_{16: 1}$; summed feature 3 contains $\mathrm{C}_{16: 1} \omega 7 \mathrm{c}$, $\mathrm{C}_{16: 1} \omega 6 \mathrm{c}$ and/or iso- $\mathrm{C}_{15: 0}$ 2-OH; summed feature 8 contains $\mathrm{C}_{18: 1} \omega 7 \mathrm{c}$ and/or $\mathrm{C}_{18: 1}$ $\omega 6 \mathrm{c}$

\begin{tabular}{|c|c|c|c|c|}
\hline Fatty acid & Strain MG & A. ferrooxidans ${ }^{\mathrm{T}}$ & A. ferridurans ${ }^{\mathrm{T}}$ & A. ferriphilus ${ }^{\mathrm{T}}$ \\
\hline $\mathrm{C}_{12: 0}$ & 5.7 & 8 & 6.6 & 5.7 \\
\hline $\mathrm{C}_{13:} \mathrm{AT} 12-13$ & - & 11 & - & 0.4 \\
\hline $\mathrm{C}_{14: 0}$ & 0.4 & - & 0.3 & 0.2 \\
\hline $\mathrm{C}_{15: 0}$ & - & - & 0.7 & - \\
\hline $\mathrm{C}_{15: 0} 3-\mathrm{OH}$ & - & - & 0.5 & - \\
\hline $\mathrm{C}_{16: 0}$ & 17.6 & 18 & 15.6 & 7.5 \\
\hline $\mathrm{C}_{16: 0} 2-\mathrm{OH}$ & 2.1 & - & 1.2 & 0.5 \\
\hline $\mathrm{C}_{16: 0} 3-\mathrm{OH}$ & 2.4 & - & 0.9 & 2.7 \\
\hline$C_{16: 1}$ & - & 21 & - & - \\
\hline $\mathrm{C}_{16: 1} \omega 5 \mathrm{c}$ & - & - & - & 0.4 \\
\hline $\mathrm{C}_{17: 0}$ & 0.9 & 6 & 1.9 & 0.5 \\
\hline $\mathrm{C}_{17: 0}$ cyclo & 3.1 & - & 6.7 & - \\
\hline $\mathrm{C}_{17: 0} 2-\mathrm{OH}$ & 0.3 & - & - & 0.1 \\
\hline$C_{17: 1} \omega 6 c$ & - & - & - & 0.4 \\
\hline $\mathrm{C}_{17: 1} \omega 8 \mathrm{c}$ & 0.4 & 0.5 & 0.7 & 0.6 \\
\hline $\mathrm{C}_{18: 0}$ & 0.8 & 0.5 & 1.5 & 0.9 \\
\hline $\mathrm{C}_{18: 0} 2-\mathrm{OH}$ & 0.2 & - & - & 0.5 \\
\hline $\mathrm{C}_{18: 0} 3-\mathrm{OH}$ & 0.4 & - & - & 0.1 \\
\hline $\mathrm{C}_{18: 1} \omega 5 \mathrm{c}$ & 0.2 & - & 0.6 & - \\
\hline $\mathrm{C}_{18: 1} \omega 7 \mathrm{c}$ & 24.1 & 21.5 & 16.6 & 33.8 \\
\hline $\mathrm{C}_{18: 1} 2-\mathrm{OH}$ & 3.3 & - & 0.9 & 10.3 \\
\hline 11 methyl $\mathrm{C}_{18: 1} \omega 7 \mathrm{c}$ & - & - & 0.3 & - \\
\hline $\mathrm{C}_{19: 0} 10$ methyl & 0.6 & & & 1.0 \\
\hline $\mathrm{C}_{19: 0}$ cyclo $\omega 8 \mathrm{c}$ & 5.2 & 14.5 & 17.5 & - \\
\hline $\mathrm{C}_{20: 2} \omega 6,9 \mathrm{c}$ & - & - & 0.4 & - \\
\hline Summed feature $1^{*}$ & 0.2 & - & 0.3 & - \\
\hline Summed feature $2 *$ & 9.0 & - & 9.9 & 10.14 \\
\hline Summed feature $3 *$ & 23.1 & - & 14.9 & 21.57 \\
\hline Summed feature $8^{*}$ & 24.1 & - & - & - \\
\hline
\end{tabular}


physiological and phylogenetic variabilities of the novel species and reveal its wider geographical and ecological distribution.

\section{Description of Acidithiobacillus ferrianus sp. nov.}

Acidithiobacillus ferrianus (fer.ri.a'nus. L. neut. n. ferrum iron; L. masc. n. Ianus, Roman god of gates and duality, often depicted with two opposite-facing heads); N.L. masc. $n$. ferrianus, referring to its ability both to oxidize and reduce iron.

Gram-negative, motile, flagellated, straight rods (1.2-2.5 $\mu \mathrm{m}$ in length) that do not form endospores. Forms ferric iron-stained colonies on acidic ferrous iron-containing solid media. Obligate chemolithoautotroph, capable of growth using ferrous iron, elemental sulfur or hydrogen as electron donors. Poor growth on tetrathionate. Facultative anaerobe, capable of coupling oxidation of ferrous iron, sulfur and hydrogen to reduction of molecular oxygen, and oxidation of sulfur and hydrogen to reduction of ferric iron. Mesophilic and acidophilic with optimum growth about $\mathrm{pH}$ 2 and $30^{\circ} \mathrm{C}$. The $\mathrm{G}+\mathrm{C}$ content of the chromosomal DNA of the type strains is $58.2 \%$. The type strain, A. ferrianus strain $\mathrm{MG}^{\mathrm{T}}\left(=\mathrm{DSM} 107098^{\mathrm{T}},=\mathrm{JCM} 33084^{\mathrm{T}}\right.$ ) was isolated from an acidic pond close to the geothermal site at Kalamos on the South coast of the island of Milos, Greece.

Acknowledgements Technical assistance of Sara Baker (University of Warwick), Barry M. Grail (Bangor University) and Yasna Gallardo (Fundación Ciencia y Vida) is gratefully acknowledged.

Funding This work was supported in part by BHP Billiton Chile Inc. (PN), the Natural Environment Research Council, UK (CF and DBJ, Grant ref. NE/L014076/1) and the Comisión Nacional de Investigación Científica y Tecnológica (under Grants FONDECYT 1181251 (R.Q.), the Programa de Apoyo a Centros con Financiamiento Basal AFB170004 (R.Q.), CONICYT-PFCHA/Doctorado Nacional/20171049 (A.M.B.), CONICYT, PAI/Convocatoria Nacional Subvencion a la Instalación en la Academia Convocatoria 2019, PAI77190083 (M.C.), and the Millennium Science Initiative, Ministry of Economy, Development and Tourism of Chile (under Grant "Millennium Nucleus in the Biology of the Intestinal Microbiota"; A.M.B., M.C. and R.Q.).

\section{Compliance with ethical standards}

Conflict of interest The authors confirm that there are no conflicts of interest.

Open Access This article is licensed under a Creative Commons Attribution 4.0 International License, which permits use, sharing, adaptation, distribution and reproduction in any medium or format, as long as you give appropriate credit to the original author(s) and the source, provide a link to the Creative Commons licence, and indicate if changes were made. The images or other third party material in this article are included in the article's Creative Commons licence, unless indicated otherwise in a credit line to the material. If material is not included in the article's Creative Commons licence and your intended use is not permitted by statutory regulation or exceeds the permitted use, you will need to obtain permission directly from the copyright holder. To view a copy of this licence, visit http://creativecommons.org/licenses/by/4.0/.

\section{References}

Amouric A, Brochier-Armanet C, Johnson DB, Bonnefoy V, Hallberg KB (2011) Phylogenetic and genetic variation among Fe(II)oxidizing acidithiobacilli supports the view that these comprise multiple species with different ferrous iron oxidation pathways. Microbiology 157:111-122. https://doi.org/10.1099/mic.0.04453 7-0

Castro M, Deane SM, Ruiz L, Rawlings DE, Guiliani N (2015) Diguanylate cyclase null mutant reveals that c-Di-GMP pathway regulates the motility and adherence of the extremophile bacterium Acidithiobacillus caldus. PLoS ONE 10(2):e0116399. https://doi.org/10.1371/journal.pone.0116399

Castro M, Moya-Beltrán A, Covarrubias PC, Gonzalez M, Cardenas JP, Issotta F, Nuñez H, Acuña L, Encina G, Holmes DS, Johnson DB, Quatrini R (2017) Draft genome sequence of the type strain of the sulfur-oxidizing acidophile, Acidithiobacillus albertensis (DSM 14366). Stand Genomic Sci 12:77. https://doi. org/10.1186/s40793-017-0282-y

Falagán C, Johnson DB (2016) Acidithiobacillus ferriphilus sp. nov.: a facultatively anaerobic iron- and sulfur-metabolising extreme acidophile. Int J Syst Evol Microbiol 66:206-211. https://doi. org/10.1099/ijsem.0.000698

Falagán C, Moya-Beltrán A, Castro M, Quatrini R, Johnson DB (2019) Acidithiobacillus sulfuriphilus sp. nov.: an extremely acidophilic sulfur-oxidizing chemolithotroph isolated from a neutral pH environment. Int J Syst Evol Microbiol 69:29072913. https://doi.org/10.1099/ijsem.0.003576

Goris J, Konstantinidis KT, Klappenbach JA, Coenye T, Vandamme P, Tiedje JM (2007) DNA-DNA hybridization values and their relationship to whole-genome sequence similarities. J Syst Evol Microbiol 57:81-91. https://doi.org/10.1099/ijs.0.64483-0

Hallberg KB, Thompson HEC, Boeselt I, Johnson DB (2001) Aerobic and anaerobic sulfur metabolism by acidophilic bacteria. In: Ciminelli VST, Garcia O Jr (eds) Biohydrometallurgy: fundamentals, technology and sustainable development, process metallurgy 11A. Elsevier, Amsterdam, pp 423-431

Hallberg KB, González-Toril E, Johnson DB (2010) Acidithiobacillus ferrivorans sp. nov.; facultatively anaerobic, psychrotolerant, iron- and sulfur-oxidizing acidophiles isolated from metal mine-impacted environments. Extremophiles 14:9-19. https:// doi.org/10.1007/s00792-009-0282-y

He Z, Xiao S, Xie X, Zhong H, Hu Y, Li Q, Gao F, Li G, Liu J, Qiu G (2007) Molecular diversity of microbial community in acid mine drainages of Yunfu sulphide mine. Extremophiles 11:305-314. https://doi.org/10.1007/s00792-006-0044-z

Hedrich S, Johnson DB (2013a) Acidithiobacillus ferridurans, sp. nov.; an acidophilic iron-, sulfur- and hydrogen-metabolizing chemolithotrophic gammaproteobacterium. Int J Syst Evol Microbiol 63:4018-4025. https://doi.org/10.1099/ijs.0.04975 9-0

Hedrich S, Johnson DB (2013b) Aerobic and anaerobic oxidation of hydrogen by acidophilic bacteria. FEMS Microbiol Lett 349:4045. https://doi.org/10.1111/1574-6968.12290

Johnson DB, Hallberg KB (2007) Techniques for detecting and identifying acidophilic mineral-oxidising microorganisms. In: Rawlings DE, Johnson DB (eds) Biomining. Springer, Berlin, pp 237-262. https://doi.org/10.1007/978-3-540-34911-2_12 
Johnson DB, Hedrich S, Pakostova E (2017) Indirect redox transformations of iron, copper and chromium catalyzed by extremely acidophilic bacteria. Front Microbiol 8: Article 211. https://doi. org/10.3389/fmicb.2017.00211

Katoh K, Standley DM (2013) MAFFT multiple sequence alignment software version 7: improvements in performance and usability. Mol Biol Evol 30:772-780. https://doi.org/10.1093/molbev/mst01 0

Kelly DP, Wood AP (2000) Reclassification of some species of Thiobacillus to the newly designated genera Acidithiobacillus gen. nov., Halothiobacillus gen. nov., and Thermothiobacillus gen. nov. Int J Syst Evol Microbiol 50:511-516. https://doi.org/10.1099/00207 713-50-2-511

Meier-Kolthoff JP, Auch AF, Klenk H-P, Göker M (2013) Genome sequence-based species delimitation with confidence intervals and improved distance functions. BMC Bioinform 14:60. https://doi. org/10.1186/1471-2105-14-60

Méndez MO, Neilson JW, Maier RM (2008) Characterization of a bacterial community in an abandoned semiarid lead-zinc mine tailing site. Appl Environ Microbiol 74:3899-3907. https://doi. org/10.1128/AEM.02883-07

Ňancucheo I, Rowe OF, Hedrich S, Johnson DB (2016) Solid and liquid media for isolating and cultivating acidophilic and acidtolerant sulfate-reducing bacteria. FEMS Microbiol Lett. https:// doi.org/10.1093/femsle/fnw083

Norris PR, Clark DA, Owen JP, Waterhouse S (1996) Characteristics of Sulfobacillus acidophilus sp. nov. and other moderately thermophilic mineral-sulphide-oxidizing bacteria. Microbiology 142:775-783. https://doi.org/10.1099/00221287-142-4-775

Norris PR, Laigle L, Slade S (2018) Cytochromes in anaerobic growth of Acidithiobacillus ferrooxidans. Microbiology 33:152-155. https://doi.org/10.1099/mic.0.000616
Nuñez H, Moya-Beltrán A, Covarrubias PC, Issotta F, Cardenas, JP et al (2017) Molecular systematics of the genus Acidithiobacillus: insights into the phylogenetic structure and diversification of the taxon. Front Microbiol 8: Article 30. https://doi.org/10.3389/ fmicb.2017.00030

Pronk JT, De Bruyn JC, Bos P, Kuenen JG (1992) Anaerobic growth of Thiobacillus ferrooxidans. Appl Environ Microbiol 58:2227-2230

Shimada MK, Nishida T (2017) A modification of the PHYLIP program: a solution for the redundant cluster problem, and an implementation of an automatic bootstrapping on trees inferred from original data. Mol Phylogenet Evol 109:409-414. https://doi. org/10.1016/j.ympev.2017.02.012

Stackebrandt E, Ebers J (2006) Taxonomic parameters revisited: tarnished gold standards. Microbiol Today 33:152-155

Tan G-L, Shu W-S, Hallberg KB, Li F, Lan C-Y et al (2008) Culturable and molecular phylogenetic diversity of microorganisms in an open-dumped, extremely acidic $\mathrm{Pb} / \mathrm{Zn}$ mine tailings. Extremophiles 12:657-664. https://doi.org/10.1007/s00792-008-0171-9

Williams KP, Kelly DP (2013) Proposal for a new class within the phylum Proteobacteria, Acidithiobacillia classis nov., with the type order Acidithiobacillales, and emended description of the class Gammaproteobacteria. Int J Syst Evol Microbiol 63:2901-2906. https://doi.org/10.1099/ijs.0.049270-0

Yang Y, Li Y, Sun Q-Y (2014) Archaeal and bacterial communities in acid mine drainage from metal-rich abandoned tailing ponds, Tongling, China. Trans Nonferrous Met Soc China 24:3332-3342. https://doi.org/10.1016/S1003-6326(14)63474-9

Publisher's Note Springer Nature remains neutral with regard to jurisdictional claims in published maps and institutional affiliations. 